\title{
The strength of welded structures at low climatic temperatures
}

\author{
Sergey Sokolov ${ }^{1}$, Ivan Vasilyev ${ }^{1 *}$, and Konstantin Manzhula ${ }^{1}$ \\ ${ }^{1}$ Peter the Great St.Petersburg Polytechnic University, 195251 St.Petersburg, Polytechnicheskaya, 29, Russian Federation
}

\begin{abstract}
Methods for the selection of steels for metal structures were analyzed in accordance with the normative documents GOST 32578-2013, ISO 20332-2015 and F.E.M.1.001. As the example the choice of steel 09G2S was confirmed for a metal structure of a crane, operated at a temperature of minus $55^{\circ} \mathrm{C}$. To confirm the correctness of the choice of steel for this design and justify the allowable size of defects, welded samples were tested at temperatures from plus 20 to minus $60^{\circ} \mathrm{C}$.
\end{abstract}

\section{Introduction}

Implementation of economic and defense activities in the northern regions of Russia involves the using of various transport, construction, technological equipment, large-sized communication devices and other objects, the main supporting element of which are welded structures. This type of structure belongs to the category of ordinary [1]. These constructions should remain operable for a sufficiently long service life (usually 10 to 20 years) in conditions of low climatic temperatures, the effects of intensive operating loads and the corrosive effects of the environment. The main design criteria for these constructions are strength and fatigue resistance. The existing normative methods of structural design calculations in most cases allow them to provide sufficient reliability. However, in the event of unfavorable combinations of several factors that reduce the plasticity of the material, structural failure can occur [2 - 5].

At present, the most effective theory of structural strength analysis is fracture mechanics [6-8]. In cases where fracture occurs with substantial plastic deformations, the concepts of nonlinear fracture mechanics such as the J-integral and cracktip opening displacement (CTOD) are applied to calculations within the mechanics of fracture [9-11], etc. The application of these approaches to the analysis of the strength of ordinary structures with fracture-like defects is complicated by the absence of a database of critical values of the J-integral and CTOD for typical low-carbon steels which used in constructions and heat-affected zones for welds. The determination of a J-integral or opening at the top of a crack located in the stress concentration zone, characteristic of an ordinary structure, requires a special highly professional investigation that goes beyond the design process. In addition, the methods of nonlinear fracture mechanics do not allow for the influence of residual welding stresses, which in large structures can be very significant [2, 12-14]. The alternative local strength criteria, strength and deformation are developed for the solvation these problems [1,15-18].

To increase the reliability of engineering calculations, it is necessary to accumulate experimental data on the strength of welded assemblies. The following factors influence the occurrence of failure in a welded structure:

- Negative temperature;

- Concentration of stresses which creating zones of increased stresses and volumetric stress state with components of the same sign;

- Residual welding stresses;

- Non-uniform material structure in the zone of temperature influence of the welded seam.

Engineering methods for calculating structures do not provide an opportunity to take into account the influence of these factors. The main method of protecting ordinary structures from brittle fracture is the choice of steel, which retains plasticity over the entire range of operating temperatures.

In accordance with russian, european and international standards, the criterion for the suitability of steel for use in a metal structure operated at low climatic temperatures is the value of Impact energy determined at a certain temperature. The value of this temperature depends on the characteristics of the structure and the conditions of its operation.

\footnotetext{
${ }^{1}$ Corresponding author: vassilyev.ivan.iv@gmail.com
}

In normative documents GOST 32578-2013, ISO 20332-2015 and F.E.M.1.001 [19-21], the temperature value is determined depending on the value of the sum of several coefficients. 


$$
Z_{\Sigma}=\sum_{i} Z_{i}
$$

Each of these coefficients characterizes the influence of one of the factors contributing to brittle fracture. In this paper the possibility of using high-quality steel $09 \mathrm{G} 2 \mathrm{~S}-15$ for the manufacture of a responsible crane construction designed for operation in the North at a temperature of minus $55^{\circ} \mathrm{C}$ was investigated.

To assess the suitability of steel due to these regulatory documents, the following parameters are used from the design documentation: operating temperature minus 55 ${ }^{\circ} \mathrm{C}$; material steel 09G2S-15 according to GOST 19281-2014; allowable value of stress $[\sigma]=235 \mathrm{MPa}$; the maximum thickness of the main elements parts $t=14 \mathrm{~mm}$; the maximum nominal stress in the construction $\sigma_{\max }=165 \mathrm{MPa}$; the endurance limit for the range of stress $\Delta \sigma_{c}=70 \mathrm{MPa}$.

In accordance with GOST 32578-2013, the cold resistance condition is determined depending on the operating temperature, the level of operating stresses and the thickness of the rolled stock. In application to the considered construction, the value of the total indicator is obtained:

$$
Z_{\Sigma}=Z_{1}+Z_{2}+Z_{3}=9+2,4+0,7=12,1
$$

This means that the steel must be with following parameters $\mathrm{KCV} \geq 33.7 \mathrm{~J} / \mathrm{cm}^{2}$ at a temperature of minus $20^{\circ} \mathrm{C}$.

The ISO 20330 standard contains 5 partial factors of influence. They take into account the operating temperature, the yield stress, the thickness of the rolled product, the endurance limit and the level of the maximum operating stresses. The operating temperature range for this standard is limited to minus $50^{\circ} \mathrm{C}$ (estimated at 6 points), so for this analysis it was necessary to extrapolate the dependence to minus $55^{\circ} \mathrm{C}$ (7 points). In summary, for this design, the following is obtained:

$$
Z_{\Sigma}=Z_{1}+Z_{2}+Z_{3}+Z_{4}+Z_{5}=7+1+1+2-1=10
$$
C.

This means that the steel should provide impact energy $\mathrm{KC}=27 \mathrm{~J}\left(\mathrm{KCV}=33.7 \mathrm{~J} / \mathrm{cm}^{2}\right)$ at a temperature of minus $20^{\circ}$

The rules of F.E.M. 1.001 define the requirements of cold resistance for three particular indicators, which take into account the operating temperature, the thickness of the rolled product and the level of the maximum operating stresses. The sum of the values of these indicators for this design is:

$$
Z_{\Sigma}=Z_{1}+Z_{2}+Z_{3}=9+2,4+0,75=12,15
$$

This value requires using the steel with an impact toughness of $\mathrm{KCV}=35 \mathrm{~J} / \mathrm{cm}^{2}$ at a temperature of minus $20^{\circ} \mathrm{C}$. The obtained data indicate that the considered standards are practically unified. There is no necessary to determine the value of $\mathrm{KCV}$ at the temperature minus $20^{\circ} \mathrm{C}$ for steel 09G2S-15 In GOST 19281-2014. However, according to the results of our tests, it has Charpy specimens $\mathrm{KCV}=48-60 \mathrm{~J} / \mathrm{cm}^{2}$ at a temperature of $-20^{\circ} \mathrm{C}$. Thereby, the steel used in this construction satisfied the normative requirements.

A linear scheme of summarizing the influence of individual factors that hamper the development of plastic deformations is adopted in these methods, although it is known that they are interdependent. For example, the influence of the concentration of stresses and the thickness of rolled products practically does not appear at normal temperatures and is substantially manifested at low temperatures. These methods do not take into account the influence of residual welding stresses, the quality of manufacturing of welded structures and the possibility of crack-like deformations or fatigue cracks in them. In addition, the use of nominal stresses as a criterion for loading the structure causes inconvenience in those cases when the design calculation is performed by the finite element method.

In connection with what was said in this paper, the research was made of the behavior of $09 \mathrm{G} 2 \mathrm{~S}-15$ steel as part of a welded assembly with a very sharp concentrator under conditions of low temperatures.

\section{Methods}

The tests were carried out on samples from sheet of 09G2S-15 steel, the same batch used for crane construction. The mechanical characteristics of the material were established as a result of testing samples of type III, №6 in accordance with GOST 1497 at temperature $T_{C}=20^{\circ} \mathrm{C}$. The obtained values of the characteristics are given below:

$\sigma_{y}=335 \mathrm{MPa} ; \sigma_{\text {в }}=500 \mathrm{MPa} ; \delta_{5}=0,35 ; \psi=0,79$. Tests of samples with a V-notch for impact bending in accordance with GOST 9454 (type 11) were carried out at temperatures of $+20^{\circ} \mathrm{C},-20^{\circ} \mathrm{C},-40^{\circ} \mathrm{C},-60^{\circ} \mathrm{C}(\mathrm{Fig}$. 1). 2).

The welded sample consisted of four plates welded by longitudinal butt seams with two-sided edge preparation (Fig. 
The samples were loaded by stretching on an Instron tensile machine at a speed of $20 \mathrm{~mm} / \mathrm{min}$. Six samples were tested in the state after welding. A deformation diagram was recorded in the coordinates [force-displacement] during the tests (Fig. 3).

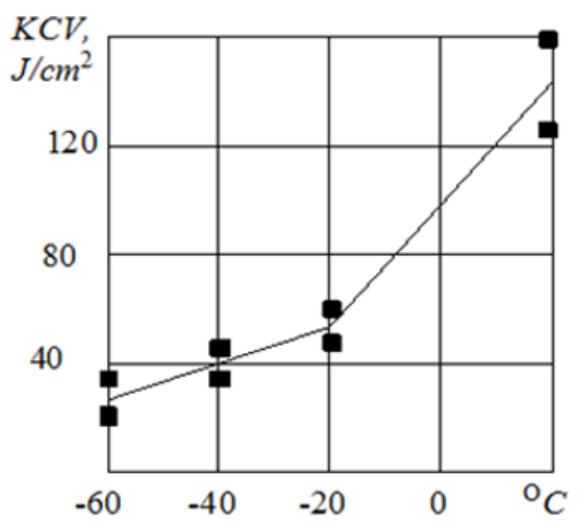

Fig. 1. Standard Charpy V-notch test results

\section{Results and Discussion}

In the samples tested in the temperature range from $+20^{\circ} \mathrm{C}$ to $-40^{\circ} \mathrm{C}$, considerable plastic deformation was observed before the destruction, which led to a substantial crack opening and blunting. The weld metal in the crack tip at temperatures up to minus $40^{\circ} \mathrm{C}$ inclusive was failure viscously along an oblique cross section. Further destruction had a quasi-brittle character with the formation of a chevron relief. At a temperature of minus $60^{\circ} \mathrm{C}$, the weld metal and the rest of the cross section were failure by an avulsion in the plane of the cross section. The destruction of all samples occurred at the nominal stress, close to the ultimate strength of material.

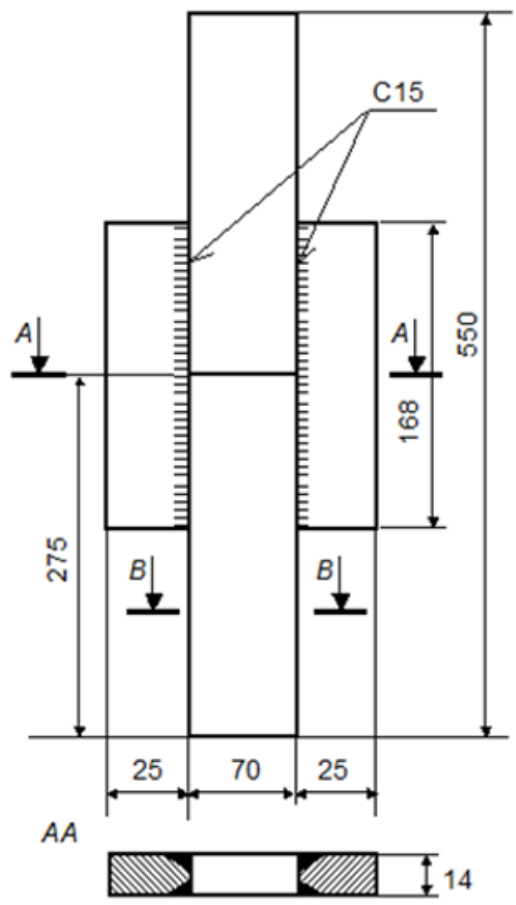

Fig. 2. Scheme of test specimens

There are two jumps are seen corresponding to the rupture of the weld metal on the diagram of the deformation of the sample at a temperature minus $60^{\circ} \mathrm{C}$ (Fig. 3).

This is due to the fact that the destruction occurred not simultaneously from two sides in consequence of inaccurate loading. In samples tested in rigid grips, it is very difficult to provide a central loading without bending. The load of the first jump of the diagram $F_{c}=174 \mathrm{kN}$ can be used to estimate the value of the critical stress intensity factor $K_{c}$. It is calculated as:

$$
K_{c}=\xi_{a} \sigma_{b} \sqrt{\pi a}
$$

Nominal stress in gross cross-section: $\sigma_{b}=F_{c} / A_{b}=104 \mathrm{MPa} . K$-calibration was calculated as [20]: 


$$
\xi_{a}=\left(1-0,025 \alpha^{2}+0,06 \alpha^{4}\right) \sqrt{\sec (\pi \alpha / 2)}=1,91
$$

In this case:

$$
\alpha=2 a / B
$$

As a result, the value of $K_{c}$ is $K_{c}=66 \mathrm{MPa} \sqrt{ }$. Given the inaccuracy of loading, this estimate can be considered underestimated. This value does not contradict the results of research [21], where samples were tested at negative temperatures from steel A533B $\left(\sigma_{y}=352 \mathrm{MPa}, \sigma_{u}=600 \mathrm{MPa}, \delta=0,16, \psi=0,63\right)$, which belongs to the same class of strength. In that work, compact samples were used, the dimensions of which provided the fulfillment of the conditions of plane deformation, in contrast to our tests. At a temperature of minus $60^{\circ} \mathrm{C}$, the values of $K_{1 c}=55 \mathrm{MPa} \sqrt{\mathrm{m}}$ were obtained there. Since in this paper the tests were carried out on samples made from the same rolled product as the actual structure, the results obtained can be applied to determine the requirements for the quality of its manufacture.

Cracks and cracks-like defects appear in welded joints creating a stress concentration. As shown in [23], the concentrators in metal structures can be represented as a two-level system. The upper level forms the general geometry of the assembly, which creates a common low-gradient stress field (design stresses). The lower level is the local geometry of the weld joint, which forms a local stress concentration in the region immediately adjacent to the seam.

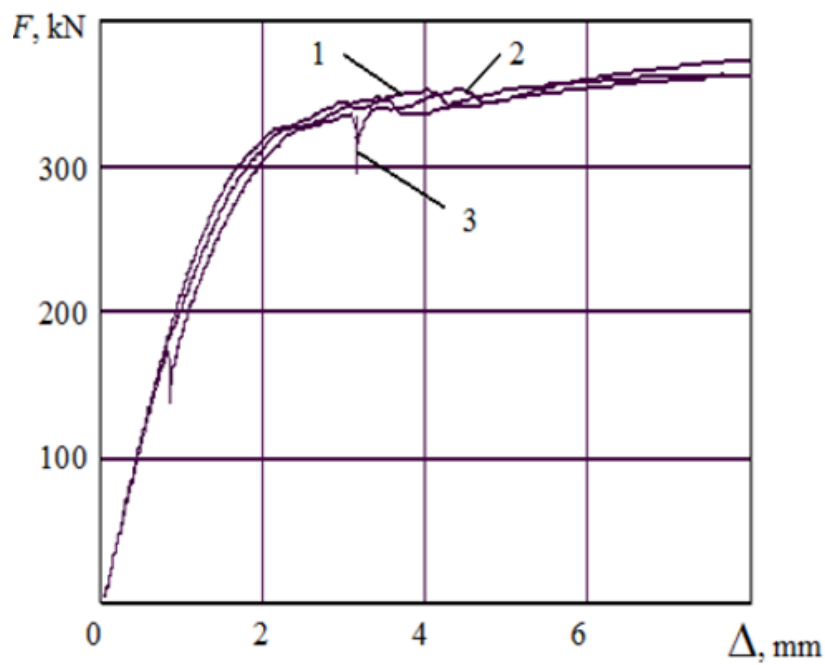

Fig. 3. Diagrams of stretching of specimens at temperatures of $-40^{\circ} \mathrm{C}(1$ and 2$)$ and $-60^{\circ} \mathrm{C}(3)$

In this analysis of the strength of the crane construction, the vertex of a possible crack-like defect that is in the field of action of the high-level concentrator creates the lower concentration level forms. This field can be considered nominal for analyzing the behavior of the defect under load. The upper level of concentration is revealed in the calculation of the finite element model with the dimensions of the elements about $2 t(t$ is the thickness of the element) [23]. Calculation of the crane construction showed that the maximum stress of the upper level is $=220 \mathrm{MPa}$ ( $35 \%$ more than the nominal stress $=165 \mathrm{MPa})$.

Therefore, in order to estimate the value of an admissible defect in the construction, following condition can be used:

$$
K_{1} \leq K_{c} / n_{K}
$$

$n_{K}$ - is the safety factor for the crack resistance of the construction, which takes into account the effect of residual stresses and the spread of the values of $K_{l}$ and $K_{n}$. We take the $n_{K}=1,3$. Consequently, an admissible defect or a crack is limited by the following condition:

$$
a \leq \frac{1}{\pi}\left(\frac{K_{c}}{\xi_{a} \sigma_{n} n_{K}}\right)^{2}
$$

If we assume for a small edge crack $\xi_{a}=1,12$, then we get $a \leq 14 \mathrm{~mm}$. This means that if the construction is subjected to extreme loading in conditions of extremely low operating temperatures, an edge crack or a crack-like defect will not develop if its characteristic size does not exceed $14 \mathrm{~mm}$, that is, the thickness of the rolled product.

This condition shows that, despite the full compliance of the used steel with the requirements of the standards for cold resistance, in the event of a technological defect or a fatigue crack with a size of more than $14 \mathrm{~mm}$ appearing in the construction, defect development or destruction may occurred. 


\section{Conclusion}

a) Analysis of engineering methods for the selection of steel for welded metal structures operated in low climatic temperatures, and the results of tests of welded specimens showed that these methods provide protection for high-quality fabricated structures against the occurrence of brittle fracture. However, these methods do not allow to justify the allowable size of the defect in welded joints.

b) Testing of welded specimens from full-scale rolled metal with a crack-like concentrator makes it possible to determine the maximum size of a welding defect that does not begin to develop when exposed to operational loads. The use of experimental data takes into account changes in the properties of steel in the heat-affected zone of the weld and the effect of residual welding stresses.

c) By the example of a crane designed for operation at minus $55^{\circ} \mathrm{C}$, it is shown that steel $09 \mathrm{G} 2 \mathrm{~S}-15$ ensures the operability of its metal construction, provided that it does not contain defects, damage or fatigue cracks larger than $14 \mathrm{~mm}$ in size.

\section{References}

1. S. Sokolov, A. Grachev, Int. Rev. Mech. Eng., 12(5), 448-453 (2018)

2. G. Shi, Y. Chen, Adv. Struct. Eng., 21, 1376-1387, (2018)

3. Brittle Fracture. Elasticity.Toughness and Liberty Ship, Metallurgical Associates, Inc., available at: http://metassoc.com/?s=spring+2011

4. M.R. Garifullin, A.V. Barabash, E.A. Naumova, O.V. Zhuvak, T. Jokinen, M. Heinisuo, Mag. Civ. Eng. 63, 53-76 (2016)

5. I.N. Priadko, V.P. Mushchanov, H. Bartolo, N.I. Vatin, I.N. Rudnieva, Mag. Civ. Eng. 65, $27-41$ (2016)

6. D. Deng, Mater. Des., 30 (2), 359-366 (2009)

7. H. Dai, J. Francis, H. Stone, H. Stone, H. Bhadeshia, P. Withers. Metall. Mater. Trans., 39A, 3070-3078 (2008)

8. $\quad$ M. Barsom., S. Rolf, Fracture and Fatigue Control in Structures. Application of Fracture Mechanics (PTR Prentice Hall, USA, 1987)

9. S. Atluri, Computational Methods in the Mechanics of Fracture vol 2, (Elsevier Science Publishers B. V., Amsterdam, 1986)

10. X. Zhu, J. Joyce, Eng. Fract. Mech., 85, 1-46, (2012)

11. S. Dugdale, J. Mech. Phys. Solids, 8(2), 105-108 (1960)

12. T. Vadholm, Investigation of low temperature toughness and crack initiation in welded structural steels, Master thesis (NTNU, Trondheim, 2014)

13. S. Sedmak, A. Sedmak, I. Camagic, Frattura integr. strutt., 12, 371-382 (2018)

14. R. Goyal, S. Bogdanov, Eng. Fail. Anal., 93, 340-355 (2018)

15. S. Xu, H. Reinhardt, Int. J. Fract., 98(2), 151-177 (1999)

16. S. Mariani, U. Perego, Int. J. Numer. Meth. Eng., 58, 103-126 (2003)

17. R. Hertzberg, Deformation and fracture mechanics of engineering materials (Wiley, New-York, 1989)

18. J. Rice, J. Appl. Mech, 55(1), 98-103 (1988)

19. GOST 32578-2013. Cranes for lifting. Steel structures. Metal constructions. Requirements for materials. (Standartinform, Moscow, 2015)

20. ISO 20332:2008 (2008) Cranes - Proof of competence of steel structures (International Organization for Standardization, Geneva, $\mathrm{CH}$ )

21. H. Murakami, Stress intensity factors handbook (Pergamon press, Oxford etc., 1987)

22. E. Wessel, Eng. Fract. Mech., 1, 77-82 ( 1968)

23. S. Sokolov, Russ. Engin. Res., 38(3), 151-156 (2018) 